\title{
Research Paper: Horticulture Therapy Effects on Memory and Psychological Symptoms of Depressed Male Outpatients
}

\author{
Ali Hoseinpoor Najjar ${ }^{*}$ (D), Elham Foroozandeh² (D), Hossein Ali Asadi Gharneh ${ }^{3}$ (D)
}

1. Department of General Psychology, Faculty of Education \& Psychology, Isfahan (Khorasgan) Branch, Islamic Azad University, Isfahan, Iran.

2. Department of Psychology, Naein Branch, Islamic Azad University, Naein, Iran.

3. Department of Horticultural Sciences, Faculty of Agriculture and Natural Resources, Isfahan (Khorasgan) Branch, Islamic Azad University, Isfahan, Iran.

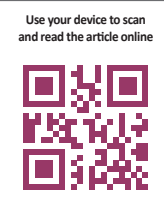

Cttation: Hoseinpoor Najjar A, Foroozandeh E, Asadi Gharneh HA. Horticulture Therapy Effects on Memory and Psychological Symptoms of Depressed Male Outpatients. Iranian Rehabilitation Journal. 2018; 16(2):147-154. http:// dx.doi.org/10.32598/irj.16.2.147

doi: : http://dx.doi.org/10.32598/irj.16.2.147

Article info:

Received: 06 Jan 2018

Accepted: 10 Apr 2018

\section{Keywords:}

Horticultural therapy,

Depression, Memory, Anxiety, Stress, Rey-osterrieth complex figure

\section{ABSTRACT}

Objectives: The aim of this study was to assess whether Horticulture Therapy (HT) is effective for the improvement of the conceptual organization function, memory and psychological symptoms of chronic depressed male outpatients.

Methods: 30 outpatients were chosen by the convenience sampling method. They were assigned to two groups, namely the experimental and the control group, by the random assignment method (each group comprising of 15 people). Outpatients were evaluated for before and after intervention by Rey-Osterrieth complex figure, and on the Depression Anxiety and Stress Scale, DASS-44.

Results: After ten sessions of horticultural therapy, the patients' scores on conceptual organization function, memory, depression, anxiety, and stress improved significantly.

Discussion: Although horticultural therapy improved outpatients' scores on conceptual organization function, memory, depression, anxiety, and stress, future study is needed, especially by engaging more patients.

\section{Introduction}

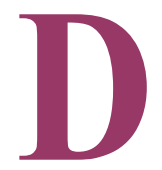

epression is one of the disorders that impose a large financial burden to the health systems in societies and affect a lot of people in all communities across the world. Today, it is estimated that depression affects 350 million people. The WHO World Mental Health (WMH) Survey conducted in 17 countries found that on an average about 1 in 20 people reported having an episode of depression [1]. Depression is a common psychiatric disorder that manifests depressed mood, loss of interest or pleasure, decreased energy, feeling of guilt or low self-worth, disturbed sleep or appetite, stress and anxiety. Depression often comes with symptoms of poor executive functions [2]. Executive functions typically are described as integrated cognitive processes that determine goal-directed and purposeful behaviors. These functions are directed to organize the daily life functions, which include the ability to formulate goals;

* Corresponding Author:

Ali Hoseinpoor Najjar, PhD

Address: Department of General Psychology, Faculty of Education \& Psychology, Isfahan (Khorasgan) Branch, Islamic Azad University, Isfahan, Iran Tel: +98 (938) 7853830

E-mail: alihoseynpoorphd@yahoo.com 
to initiate behaviors, anticipate the consequences of actions, plan and organize behaviors according to the conceptual, spatial and logical sequences; and to memorize information to do a particular task [3].

Executive functions play an important role in adapting and managing purposeful behavior. In fact, executive functions enable individuals to think and react automatically [4]. Executive functions encompass the highest cognitive functions that are necessary for purposeful behavior [5]. Executive functions are commonly associated with deficits from lesions in frontal regions and some psychiatric disorders, such as depression [6]. Recent evidences suggest that depressive disorders may increase the risks of cognitive dysfunctions [7]. The most common dysfunctions are related to the functions that are related to memory and memorization. Depressive disorders can negatively change autobiographical memory [8], recollection memory [9], working memory [10], verbal memory performance [11], and visual memory [12]. Undoubtedly, stress has been an inseparable factor of depression. There are sufficient researches that show stress and the major stressful life events as one of the best predictors of depression [13]. All people face threatening events in their life; moreover, they face numerous environmental stressors such as traffic, noise, crowd, poor housing quality, poor neighborhood quality and so on that leads them to depression [14].

According to the foregoing paragraph people live in the world where stress and stressors are inseparable components of their life and need a way to reduce the burden of stress that they suffer, consciously as well as subconsciously. Horticultural Therapy (HT) was defined as the art and science of growing flowers, vegetables, shrubs, trees and fruit trees to achieve improvement in the mental and emotional level of a person [15]. HT is known as the collection of various gardening activity processes that are used to improve the physical, mental, and spiritual health of patients. It is considered as an effective and beneficial treatment for people of all ages, backgrounds, and abilities.

The therapeutic factors of gardening activities have been understood since ancient times. In the $19^{\text {th }}$ century, Dr. Benjamin Rush, Father of American Psychiatry, reported that garden settings had curative and healing effects for people with mental illness [16]. Soderback reviewed the literature of HT and described its uses in the rehabilitation of brain-damaged patients. He showed that HT can be effective for emotional disorders, cognitive and/or sensory motor functional impairments and can increase social participation, health, well-being and life satisfaction [17]. Jones and Haight reviewed articles on the use of natural environments and plants in therapeutic interventions [18]. In recent decades, several researches have been done on Horticultural Therapy and some of them have shown the therapeutic effect of horticultural therapy on stress. Additionally, some studies have revealed that natural spaces have a positive effect on cognitive functions [19]. For instance, Strife and Downey have shown that children who had a garden in their yard or school showed a better memory, attention, and concentrate function than those who didn't have one [20]. Recently, HT has been used for Alzheimer patients as a rehabilitation tool. Detweiler et al. and Hewitt et al. both imposed HT to rehabilitate Alzheimer patients and in both the studies results demonstrated that HT increased cognitive abilities, especially memory, in patients [21, 22]. Gonzalez et al. showed that HT intervention improved the psychological symptoms of depression [23]. Moshfeghi, Reza-Bakhsh and Danesh reported similar results in a sample of depressed elderly patients [24].

Nonetheless, in Iran, unfortunately, just a few researches have been done to determine the effectiveness of the HT on Conceptual Organization Function, Memory and Psychological Symptoms of depressed people, and this very issue is the incentive of this researcher to undertake this study.

\section{Methods}

The present study is a semi experimental one with a pretest and posttest control group design. The statistical population of the present study included all chronic depressed male outpatients in the city of Isfahan, in 2015. Outpatients, who had been diagnosed with chronic depression based on DSM-5 by psychiatrists of NoorAlmahdi Mental Hospital, located in Isfahan Iran, were chosen by the convenience sampling method. They were assigned to two groups including the experimental group and control group by the random assignment method. The outpatients who did not participate in 10 sessions of the horticulture therapy were excluded from the study. Also the patients who suffered from the comorbid disorders like schizoaffective disorder or substance abuse disorder were not allowed to take part in this study. In total, 30 outpatients were randomly selected by using the Kukran formula and based on the inclusion and exclusion criteria were placed in two groups - experimental and control (15 outpatients in each group). The experimental group received horticultural therapy during 10 sessions in Noor-Almahdi Mental Hospital but the control group did not receive this therapy. These sessions lasted five weeks with two two-hour sessions per week in the garden of the hospital, in the autumn of 2015. In 
order to observe the ethical considerations, the objectives and the steps of the present study were explained to the officials of the hospital and written informed consent forms were also obtained. Subjects were evaluated before and after research by the following tests:

\section{Rey-Osterrieth Complex Figure}

Rey-Osterrieth Complex Figure Test (ROCF) is a neuropsychological test that is performed in two stages. In the first stage the subject is asked to copy and reproduce a complicated line drawing (recognition stage), and then draw the same picture based on what he/she can remember (recall stage). Many different cognitive abilities are needed for a correct performance, and it can be said that ROCF provides the evaluation of different mental functions, such as visuo-spatial abilities, memory, attention, planning, organization, working memory and executive functions [25].

It is frequently used to further explain any secondary effect of brain injury in neurological patients, to test for the presence of dementia, or to study the degree of cognitive development. Scoring parameter for this test is based on the Taylor-Osterrieth method. In this study Rey-Osterrieth complex figure is used to evaluate conceptual organization function (in the first stage) and memory function (in the second stage).

\section{Depression Anxiety and Stress Scale (DASS-44)}

Depression Anxiety Stress Scale (DASS) is a promising 42-item self-report measure of depression, anxiety, and stress [26]. Theoretically, the DASS corresponds with the tripartite model of anxiety and depression [27]. This model suggests that anxiety and depression have both shared and unique features. The correlation between anxiety and depression subscales of DASS-44 with the Beck anxiety and depression questionnaire has been reported as 0.81 and 0.47 , respectively, whereas the retest reliability depression, anxiety, and stress subscale of this test is reported $0.71,0.79$, and 0.81 respectively. Bakhshi-Poor reported the internal consistency of depression and anxiety subscale of this scale to be 0.74 and 0.89 respectively. Also, in the Iranian society the retest reliability of depression and anxiety subscales of this test with the Beck anxiety and depression questionnaire is reported to be 0.70 and 0.83 [28]. In the present study the Persian issue of this test was used. The questionnaire was answered and the tests were done before and after the intervention by patients and the raw scores were analyzed by SPPS-18 software. Variance analysis was used to interpret the results.

\section{HT Intervention}

HT intervention package has been designed by Mizuno-Matsumoto et al. (2008), a specialist in this field [29]. HT sessions are shown in Table 1.

Table 1. HT intervention

\begin{tabular}{|c|c|c|}
\hline Treatment Session & Description of Programs & $\begin{array}{l}\text { Time of This } \\
\text { Session }\end{array}$ \\
\hline First session & $\begin{array}{l}\text { Lying down in the greenhouse and imagining a fantasy garden, each outpatient should } \\
\text { choose a flower box }\end{array}$ & $60 \mathrm{~min}$ \\
\hline Second session & Combining soil with muck and pouring it in the flower boxes & $90 \mathrm{~min}$ \\
\hline Third session & Planting violets in the flower boxes and watering & $90 \mathrm{~min}$ \\
\hline Fourth session & Touching the violets, expressing the feelings, planting the marigold and watering & $90 \min$ \\
\hline Fifth session & Watering and weeding & $90 \mathrm{~min}$ \\
\hline Sixth session & Planting ice sedum and watering & $90 \min$ \\
\hline Seventh session & Watering, picking up withered flowers, touching the flowers and expressing the feelings & $90 \mathrm{~min}$ \\
\hline Eighth session & $\begin{array}{c}\text { Working on the flower box and completing flower boxes by planting more flowers and } \\
\text { filling empty spaces }\end{array}$ & $90 \mathrm{~min}$ \\
\hline Ninth session & Watering, weeding and picking up withered flowers & $90 \mathrm{~min}$ \\
\hline Tenth session & Appreciating other outpatients & $90 \mathrm{~min}$ \\
\hline
\end{tabular}




\section{Results}

Table 2 presents the means and standard deviations for all variables. As expected, the means of conceptual organization function and memory increased and the means of stress, anxiety and depression decreased in the post-test. Table 3 presents the variance analysis for all variables. As can be seen, horticultural therapy has a significant effect on improving the scores of Rey drawing $(\mathrm{P}=0.000)$ and recalling $(\mathrm{P}=0.001)$, stress, $(\mathrm{P}=0.000)$ anxiety $(\mathrm{P}=0.000)$, and depression $(\mathrm{P}=0.000)$ in the post-test.

\section{Discussion}

The results of this study show that Horticultural Therapy improved conceptual organization function and memory of outpatients in the experiment group. This finding is supported by Mizuno-matsumoto and et al. and Faber Taylor and Kuo [29, 30]. Faber Taylor and Kuo's research revealed that natural environments improved attention. According to the attention restoration theory developed by Kaplan and Kaplan, when people attend in a natural environment, their unconscious attention gets involved with this environment [31].

Table 2. The means and standard deviations of conceptual organization function (drawing stage in Rey-Osterrieth complex figure), memory (recalling stage in Rey-Osterrieth complex figure), Stress, anxiety and depression

\begin{tabular}{|c|c|c|c|c|c|}
\hline Variable & Group & Stage & Mean & Standard Deviation & Number \\
\hline \multirow{5}{*}{ Rey-drawing } & \multirow{3}{*}{ Experiment } & Post-Test & 67.20 & 20.34 & 15 \\
\hline & & Pre-test & 12.06 & 7.35 & 15 \\
\hline & & Post-test & 21.00 & 10.31 & 15 \\
\hline & \multirow{2}{*}{ Control } & Pre-test & 11.23 & 4.67 & 15 \\
\hline & & Post-test & 11.06 & 5.21 & 15 \\
\hline \multirow{5}{*}{ Rey-recalling } & \multirow{2}{*}{ Experiment } & Pre-test & 4.86 & 3.89 & 15 \\
\hline & & Post-test & 10.80 & 8.48 & 15 \\
\hline & \multirow{3}{*}{ Control } & & & & \\
\hline & & Pre-test & 6.93 & 4.45 & 15 \\
\hline & & Post-test & 6.60 & 4.28 & 15 \\
\hline \multirow{5}{*}{ Stress } & \multirow{3}{*}{ Experiment } & Pre-test & 22.06 & 3.86 & 15 \\
\hline & & Post-test & 16.40 & 4.93 & 15 \\
\hline & & & & & \\
\hline & \multirow{2}{*}{ Control } & Pre-test & 18.80 & 3.82 & 15 \\
\hline & & Post-test & 19.20 & 3.23 & 15 \\
\hline \multirow{5}{*}{ Anxiety } & \multirow{2}{*}{ Experiment } & Pre-test & 24.13 & 6.15 & 15 \\
\hline & & Post-test & 16.60 & 5.03 & 15 \\
\hline & \multirow{3}{*}{ Control } & & & & \\
\hline & & Pre-test & 17.40 & 5.91 & 15 \\
\hline & & Post-test & 17.60 & 6.55 & 15 \\
\hline \multirow{5}{*}{ Depression } & \multirow{3}{*}{ Experiment } & Pre-test & 22.80 & 5.46 & 15 \\
\hline & & & & 509 & 15 \\
\hline & & & & & \\
\hline & \multirow{2}{*}{ Control } & Pre-test & 19.93 & 5.14 & 15 \\
\hline & & Post-test & 20.26 & 3.97 & 15 \\
\hline
\end{tabular}


Table 3. Variance analysis of conceptual organization function, memory, Stress, anxiety and depression

\begin{tabular}{|c|c|c|c|c|c|c|c|}
\hline & Sources & Variable & Sum of Squares & df & Mean Square & $\mathbf{F}$ & Sig. \\
\hline \multirow{4}{*}{ Rey-drawing } & \multirow{2}{*}{ Within-subjects } & Time & 288.204 & 1 & 228.204 & 16.356 & 0.000 \\
\hline & & Time $\times$ group & 310.538 & 1 & 310.538 & 17.623 & 0.000 \\
\hline & \multirow{2}{*}{ Between-subjects } & Error & 493.383 & 28 & 17.621 & - & - \\
\hline & & Group & 434.704 & 1 & 434.704 & 4.992 & 0.340 \\
\hline \multirow{4}{*}{ Rey-recalling } & \multirow{2}{*}{ Within-subjects } & Time & 117.600 & 1 & 117.600 & 11.990 & 0.002 \\
\hline & & Time $\times$ group & 147.267 & 1 & 147.267 & 15.014 & 0.001 \\
\hline & \multirow{2}{*}{ Between-subjects } & Error & 274.633 & 28 & 9.808 & - & - \\
\hline & & Group & 17.067 & 1 & 17.067 & 0.323 & 0.574 \\
\hline \multirow{4}{*}{ Stress } & \multirow{2}{*}{ Within-subjects } & Time & 104.017 & 1 & 104.017 & 19.228 & 0.000 \\
\hline & & Time $\times$ group & 138.017 & 1 & 138.017 & 25.514 & 0.000 \\
\hline & \multirow{2}{*}{ Between-subjects } & Error & 151.467 & 28 & 5.410 & - & - \\
\hline & & Group & 0.817 & 1 & 0.817 & 0.030 & 0.863 \\
\hline \multirow{4}{*}{ Anxiety } & \multirow{2}{*}{ Within-subjects } & Time & 201.667 & 1 & 201.667 & 25.659 & 0.000 \\
\hline & & Time $\times$ group & 224.267 & 1 & 224.267 & 28.534 & 0.000 \\
\hline & \multirow{2}{*}{ Between-subjects } & Error & 220.067 & 28 & 7.860 & - & - \\
\hline & & Group & 123.267 & 1 & 123.267 & 2.025 & 0.166 \\
\hline \multirow{4}{*}{ Depression } & \multirow{2}{*}{ Within-subjects } & Time & 109.350 & 1 & 109.350 & 15.611 & 0.000 \\
\hline & & Time $\times$ group & 138.017 & 1 & 138.017 & 19.703 & 0.000 \\
\hline & \multirow{2}{*}{ Between-subjects } & Error & 196.133 & 28 & 7.005 & - & - \\
\hline & & Group & 0.417 & 1 & 0.417 & 0.010 & 0.921 \\
\hline
\end{tabular}

Iranian Rehabilitation Journal

Since natural environments have restoration benefits, attention gets recovered and subsequently causes better function for conceptual organization and memory. As for results, Horticultural Therapy improved stress and anxiety of outpatients, therapeutically. This result is in coordination with Ulrich et al.; Whitehouse et al.; Rodiek, Bodinand Hartig; Nilsson, Grahn, Corazon, Stigsdotter; and Bertoresearches. According to stress recovery theory, the first and initial response to a new environment occurs without any conscious recognition or information processing of the environment [32]. The positive and affective responses can be seen when specific environmental features are present in the environment. These features include the presence of natural content like vegetation as well as more structural features such as complexity, acceptable quality structural features like symmetries, depth, spatiality cues of ground surface texture, and absence of threats. Quick positive affective responses to these features conclude the restorative process because these features provide stress free sense, which can reduce the levels of arousal and negative feelings such as fear and anxiety. It seems that natural environments have these restorative features; therefore, Horticultural Therapy, by providing a natural environment without any threatening stimulus to do some horticultural activities, caused a decline in the stress and anxiety levels of the outpatients. The most important finding of this research was the therapeutic effect of Horticultural Therapy on plunging depression. This finding coordinated with Wichrowski and et al's research [33].

Wichrowski and et al's research conclude that Horticultural Therapy improved a depressed mood. It seemed that as much as stress and anxiety decreased, the depression went down proportionately and as much as depression decreased, the conceptual organization function and memory improved. Clearly, Horticultural Therapy was effective in increasing the conceptual organization function and memory and decreasing stress, anxiety and de- 
pression but which one of the variables was improved first by horticultural therapy, to then effect the other one, still remains to be answered. We think the research presented here is necessary to accomplish further studies.

\section{Conclusion}

It has been derived that Horticultural Therapy is one of the effective ways to decrease Psychological Symptoms and increase memory and organizational function of male chronic depressed people. Therefore, hospital psychotherapists are recommended to make use of this method to treat chronic depressed patients.

\section{Ethical Considerations}

\section{Compliance with ethical guidelines}

In order to observe the ethical considerations, the objectives and the steps of the present study were explained to the officials of the hospital and written informed consent forms were also obtained.

\section{Funding}

This study was derived from the MSc. thesis of Ali Hoseinpoor Najjar in Clinical Psychology at the Islamic Azad University of Isfahan (Khorasgan), Isfahan.

\section{Conflict of interest}

The authors declared no conflict of interest.

\section{Acknowledgements}

We hereby express our gratitude to Noor-Almahdi Mental Hospital's officials and employees as well as those male outpatients, who helped the researchers in this study.

\section{References}

[1] World Health Organization. World Suicide Prevention Day (WSPD). Geneva: World Health Organization; 2012.

[2] American Psychiatric Association. Diagnostic and Statistical Manual of Mental Disorders (DSM-5®). Washington, D.C. American Psychiatric Publishing; 2013. [DOI:10.1176/appi books.9780890425596]

[3] Gozal D, Molfese DL. Attention deficit hyperactivity disorder: From genes to patients. New York: Humana Press; 2005. [DOI:10.1385/1592598919]
[4] Brocki KC, Bohlin G. Executive functions in children aged 6 to 13: A dimensional and developmental study. Developmental Neuropsychology. 2004; 26(2):571-93. [DOI:10.1207/ s15326942dn2602_3] [PMID]

[5] Thorell LB, Lindqvist S, Bergman Nutley S, Bohlin G, Klingberg $\mathrm{T}$. Training and transfer effects of executive functions in preschool children. Developmental Science. 2009; 12(1):10613. [DOI:10.1111/j.1467-7687.2008.00745.x] [PMID]

[6] Alves M, Yamamoto T, Arias-Carrion O, Rocha N, Nardi A Machado S, et al. Executive function impairments in patients with depression. CNS \& Neurological Disorders - Drug Targets. 2014; 13(6):1026-40. [DOI:10.2174/187152731366614061 2102321]

[7] Murrough JW, Iacoviello B, Neumeister A, Charney DS, Iosifescu DV. Cognitive dysfunction in depression: Neurocircuitry and new therapeutic strategies. Neurobiology of Learning and Memory. 2011; 96(4):553-63. [DOI:10.1016/j. nlm.2011.06.006] [PMID]

[8] Park RJ, Goodyer I, Teasdale JD. Effects of induced rumination and distraction on mood and overgeneral autobiographical memory in adolescent major depressive disorder and controls. Journal of Child Psychology and Psychiatry. 2004; 45(5):996-1006. [DOI:10.1111/j.1469-7610.2004.t01-1-00291.x] [PMID]

[9] MacQueen G, Galway T, Hay J, Young L, Joffe R. Recollection memory deficits in patients with major depressive disorder predicted by past depressions but not current mood state or treatment status. Psychological Medicine. 2002; 32(2):251-8. [DOI:10.1017/S0033291701004834]

[10] Gohier B, Ferracci L, Surguladze SA, Lawrence E, El Hage W, Kefi MZ, et al. Cognitive inhibition and working memory in unipolar depression. Journal of Affective Disorders. 2009; 116(1):100-5. [DOI:10.1016/j.jad.2008.10.028] [PMID]

[11] Wang CE, Halvorsen M, Sundet K, Steffensen AL, Holte A, Waterloo K. Verbal memory performance of mildly to moderately depressed outpatient younger adults. Journal of Affective Disorders. 2006; 92(2):283-6. [DOI:10.1016/j. jad.2006.02.008] [PMID]

[12] Hammar $̊$, Schmid M. Visual memory performance in patients with major depression: A 9-month follow-up. Applied Neuropsychology: Adult. 2013; 20(3):192-6. [DOI:10.1080/090 84282.2012.670170

[13] Stroud CB, Davila J, Moyer A. The relationship between stress and depression in first onsets versus recurrences: A meta-analytic review. Journal of Abnormal Psychology. 2008; 117(1):206. [DOI:10.1037/0021-843X.117.1.206] [PMID]

[14] Steg L, van den Berg AE, De Groot JI. Environmental psychology: An introduction. Hoboken: John Wiley \& Sons; 2012

[15] Relf D, McDaniel AR, Butterfield B. Attitudes toward plants and gardening. HortTechnology. 1992; 2(2):201-4.

[16] American Horticultural Therapy Association. American Horticultural Therapy Association Definitions and Positions Washington D.C.: American Horticultural Therapy Association; 2013.

[17] Jones MM, Haight BK. Environmental transformations: an integrative review. Journal of Gerontological Nursing. 2002; 28(3):23-7. [DOI:10.3928/0098-9134-20020301-06] 
[18] Berto R. The role of nature in coping with psycho-physiological stress: A literature review on restorativeness. Behavioral Sciences. 2014; 4(4):394-409. [DOI:10.3390/bs4040394] [PMID] [PMCID]

[19] Berman MG, Kross E, Krpan KM, Askren MK, Burson A, Deldin PJ, et al. Interacting with nature improves cognition and affect for individuals with depression. Journal of Affective Disorders. 2012; 140(3):300-5. [DOI:10.1016/j. jad.2012.03.012] [PMID] [PMCID]

[20] Strife S, Downey L. Childhood development and access to nature: A new direction for environmental inequality research. Organization \& Environment. 2009; 22(1):99-122. [DOI:10.1177/1086026609333340] [PMID] [PMCID]

[21] Detweiler MB, Sharma T, Detweiler JG, Murphy PF, Lane $\mathrm{S}$, Carman J, et al. What is the evidence to support the use of therapeutic gardens for the elderly. Psychiatry Investigation. 2012; 9(2):100-10. [DOI:10.4306/pi.2012.9.2.100] [PMID] [PMCID]

[22] Hewitt P, Watts C, Hussey J, Power K, Williams T. Does a structured gardening programme improve well-being in young-onset dementia? A preliminary study. British Journal of Occupational Therapy. 2013; 76(8):355-61. [DOI:10.4276/03 0802213X13757040168270]

[23] Gonzalez MT,Hartig T,Patil GG,Martinsen EW,Kirkevold M. A prospective study of group cohesiveness intherapeutic horticulture for clinical depression. International Journal of Mental Health Nursing. 2011; 20(2):119-29. [DOI:10.1111/ j.1447-0349.2010.00689.x] [PMID]

[24] Moshfeghi G, Rezabakhsh H, Danes E. [Effectiveness of horticulture therapy on depression among older adults in nursing homes (Persian)]. The Journal ofShahidBeheshti University of Medical Sciences and Health Services. 2014; 24(86):17-26.

[25] Shin MS, Park SY, Park SR, Seol SH, Kwon JS. Clinical and empirical applications of the Rey-Osterrieth complex figure test. Nature Protocols. 2006; 1(2):892. [DOI:10.1038/ nprot.2006.115] [PMID]

[26] Lovibond PF, Lovibond SH. The structure of negative emotional states: Comparison of the Depression Anxiety Stress Scales (DASS) with the Beck Depression and Anxiety Inventories. Behaviour Research and Therapy. 1995; 33(3):335-43. [DOI:10.1016/0005-7967(94)00075-U]

[27] Brown TA, Chorpita BF, Barlow DH. Structural relationships among dimensions of the DSM-IV anxiety and mood disorders and dimensions of negative affect, positive affect, and autonomic arousal. Journal of Abnormal Psychology. 1998; 107(2):179. [DOI:10.1037/0021-843X.107.2.179] [PMID]

[28] Bakhshipoor Roodsari A, Dezhkam M, Mehryar AH, Bireshk B. [Structural relationships among anxiety and depression disorders dimensions and Expanded triple dimensions (Persian)]. Behavior and Thinking Journal. 2004; 9(4):6373.

[29] Mizuno Matsumoto Y, Kobashi S, Hata Y, Ishikawa O, Asano F. Horticultural therapy has beneficial effects on brain functions in cerebrovascular diseases. International Journal of Intelligent Computing in Medical Sciences \& Image Processing. 2008; 2(3):169-82. [DOI:10.1080/1931308X.2008.10644162]

[30] Faber Taylor A, Kuo FE. Children with attention deficits concentrate better after walk in the park. Journal of Attention
Disorders. 2009; 12(5):402-9. [DOI:10.1177/1087054708323000] [PMID]

[31] Kaplan R, Kaplan S. The experience of nature: A psychological perspective. Cambridge: Cambridge University Press Archive; 1989.

[32] Altman I, Wohlwill JF. Behavior and the natural environment. Berlin: Springer Science \& Business Media; 2012.

[33] Wichrowski M, Whiteson J, Haas F, Mola A, Rey MJ. Effects of horticultural therapy on mood and heart rate in patients participating in an inpatient cardiopulmonary rehabilitation program. Journal of Cardiopulmonary Rehabilitation and Prevention. 2005; 25(5):270-4. [DOI:10.1097/00008483200509000-00008] 
